\title{
Correction to: An in vitro and clinical dose-finding study of antifoaming effects of simethicone during colonoscopy
}

\section{Marguerite J. Kutyla ${ }^{1,2} \cdot$ Ayesha Shah $^{1,3} \cdot$ Jerome Elson $^{1} \cdot$ Vera Meeusen $^{1} \cdot$ Sam O'Connor ${ }^{1,3} \cdot$ Luke F. Hourigan $^{1,3}$. Gerald J. Holtmann ${ }^{1,3}$ (D)}

Published online: 7 February 2020

(C) Indian Society of Gastroenterology 2020

Correction to: Indian Journal of Gastroenterology 38(3): 268-272

$$
\text { https://doi.org/10.1007/s12664-019-00966-3 }
$$

In the above article, due to probable typo error with the picture and legend, the correct Fig. 1 and the Legend to the Fig. 1 are printed here:

The online version of the original article can be found at https://doi.org/ 10.1007/s12664-019-00966-3

Gerald J. Holtmann

gerald.holtmann@health.qld.gov.au

1 Department of Gastroenterology and Hepatology, Princess Alexandra Hospital, Brisbane, QLD, Australia

2 School of Pharmacy, University of Queensland, Brisbane, QLD, Australia

3 Faculty of Medicine, University of Queensland, Brisbane, QLD, Australia

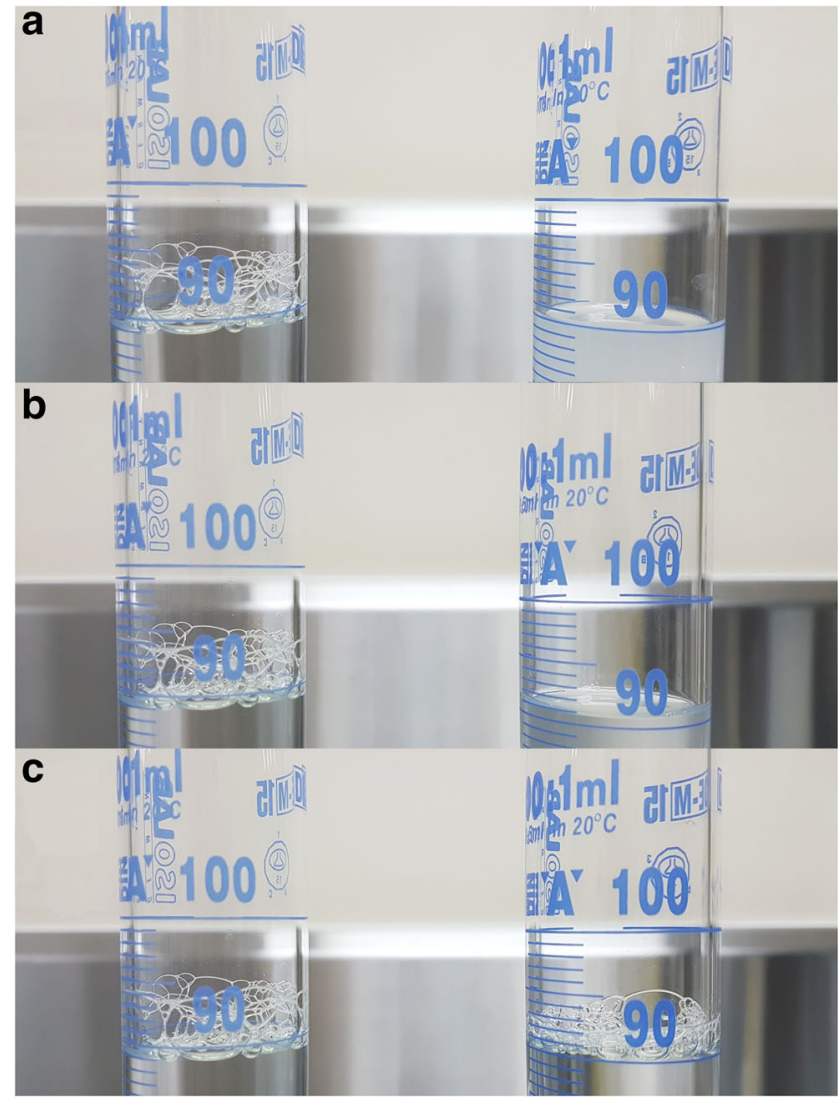

Fig. 1 Side view of standard detergent solution (left) with a $200 \mathrm{mg}$, b 20 $\mathrm{mg}$, and c $2 \mathrm{mg}$ simethicone per $100 \mathrm{~mL}$ (right)

Publisher's note Springer Nature remains neutral with regard to jurisdictional claims in published maps and institutional affiliations. 